ISSN 2089-8673

Jurnal Nasional Pendidikan Teknik Informatika (JANAPATI)

Volume 1, Nomor 1, Maret 2012

\title{
APLIKASI TEKNOLOGI GSM/GPRS PADA SISTEM DETEKSI KEBAKARAN BERBASIS MIKROKONTROLLER ATMEGA 8535
}

\author{
Oleh \\ Ade Silvia Handayani \\ Email: ade_silvia_armin@yahoo.co.id; armin.makmun@londonsumatra.com
}

\begin{abstract}
ABSTRAK
Informasi awal akan potensi kebakaran akan sangat membantu pencegahan musibah kebakaran, sehingga di butuhkan suatu sistem deteksi dan peringatan dini kebakaran yang memberikan informasi lebih awal untuk bertindak lebih cepat dan tepat. Sistem yang dikembangkan adalah dengan mendeteksi terjadinya bahaya kebakaran menggunakan telepon GSM dengan mikrokontroller AT 8535 sebagai pengendalinya. Sistem pendeteksi kebakaran ini dengan menggunakan sensor gas dan sensor suhu, dimana sensor akan mendeteksi adanya perubahan suhu (diatas $40^{\circ}$ ) dan juga tekanan gas mulai dari 500 ppm - 10.000 ppm. Mikrokontroller akan melakukan perintah untuk mengirimkan informasi data (SMS) kepada nomor telepon seluler yang telah terprogram didalam mikrokontroler ATmega 8535. Setelah dilakukan pengujian terhadap alat, sistem-sistem yang terintegrasi bekerja dengan baik sesuai dengan apa yang diharapkan dimana pengiriman informasi yang dituju sudah bisa dilakukan.
\end{abstract}

\section{Pendahuluan}

Sejalan dengan perkembangan teknologi saat ini, khususnya keamanan rumah hunian yang ditinggalkan pemiliknya ataupun dalam keadaan kosong dari bahaya kebakaran bukan hanya pencurian dan tindakan kriminal lainnya, bukanlah hal yang mengherankan apabila semakin hari manusia semakin menginginkan suatu sistem pengamanan yang lebih canggih dan modern. Sebagaimana yang diketahui solusi yang dilakukan begitu banyak. Namun tetap saja banyak kebakaran maupun bahaya akibat api tidak dapat dicegah, walaupun pengamannya dengan alat yang modern. Biasanya penyebabnya adalah karena pengaman hanya dengan alarm maupun dengan pemadam api, hal ini tidak terlalu efektif karena saat pemilik rumah tidak ada di tempat pencegahannya tidak dapat dilakukan.

Sistem pengaman dengan cara ini memungkinkan apabila terjadi kebakaran atau kenaikan suhu (di atas $40^{\circ}$ ) yang terdeteksi dengan sensor suhu dan gas maka informasi kebakaran langsung dikirimkan oleh HP base ke handphone personal yang dimiliki. Pada saat mengetahui adanya kebakaran yang tampil pada handphone pribadi yang dimiliki maka tindakan pencegahan pertama yang dapat dilakukan walaupun pada saat itu kita berada ditempat yang jauh adalah dengan menekan tombol YES pada handphone pribadi kita maka secara otomatis menggerakkan beban berupa mini pompa air yang dapat memadamkan api tersebut sehingga kita dapat mencegah kebakaran yang lebih besar.

\section{Landasan Teori}

\subsection{GSM (Global Sistem for Mobile Communication)}

GSM merupakan teknologi seluler generasi kedua yang menggunakan modulasi digital. Menyediakan kapasitas lebih besar, kualitas suara serta sekuritas yang lebih baik jika dibandingkan dengan teknologi generasi pertama. GSM merupakan teknologi Time Division Multiple Access (TDMA) sebagai interfacenya. Pada teknologi ini, suatu pita dengan frekuensi tertentu yang lebih lebar dibagi-bagi kedalam beberapa time slot. Hal ini berarti 
ISSN 2089-8673

Jurnal Nasional Pendidikan Teknik Informatika (JANAPATI)

Volume 1, Nomor 1, Maret 2012

bahwa beberapa panggilan dapat menggunakan kanal frekuensi yang sama, pada suatu slot waktu yang berbeda-beda.

\subsection{Sensor}

Sensor adalah jenis tranduser yang digunakan untuk mengubah besaran mekanis, magnetis, panas, sinar, dan kimia menjadi tegangan dan arus listrik. Sensor sering digunakan untuk pendeteksian pada saat melakukan pengukuran atau pengendalian. Beberapa jenis sensor yang banyak digunakan dalam rangkaian elektronik antara lain sensor cahaya, sensor suhu, dan sensor tekanan.

\subsection{Sensor Suhu LM 35}

Sensor suhu LM35 berfungsi untuk mengkonversi besaran panas yang ditangkap menjadi besaran tegangan. Jenis sensor suhu yang digunakan dalam sistem ini adalah IC LM35, sensor ini memiliki presisi tinggi. Sensor ini sangat sederhana dengan hanya memiliki buah 3 kaki. Kaki pertama IC LM35 dihubung kesumber daya, kaki kedua sebagai output dan kaki ketiga dihubung ke ground. Adapun gambar dan karakteristik dari IC LM35 adalah sebagai berikut :

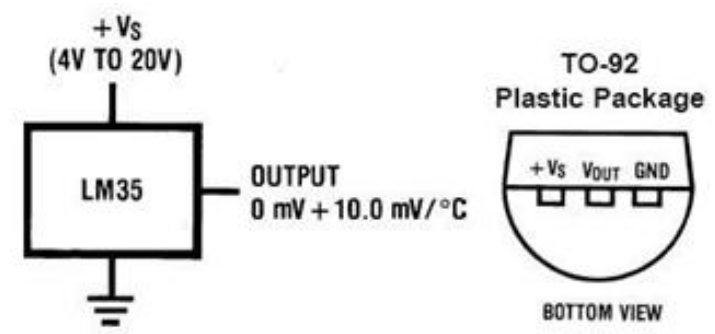

Gambar 1 IC LM 35

\subsection{Sensor Asap/Gas TGS2610}

Salah satu sensor yang memenuhi kriteria untuk mendeteksi gas LPG adalah sensor TGS 2610 buatan Figaro. Sensor akan mendeteksi kadar gas LPG secara terus-menerus dan selalu meng-update keluaran tegangan analog yang kemudian diolah oleh mikrokontroler.

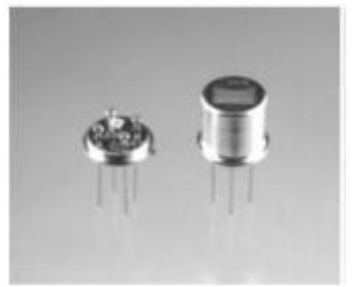

Gambar 2 Sensor TGS 2610

Spesifikasi dari sensor ini dapat mendeteksi gas Butana dan LPG dalam range $500-$ $10.000 \mathrm{ppm}$. Sensor ini bekerja berdasarkan perubahan gas terhadap resistansi dari sensor tersebut. Semakin besar kandungan dari gas LPG maka semakin kecil resistansinya dan semakin kecil kandungan dari gas LPG yang diterimanya maka resistansinya akan semakin besar. 
ISSN 2089-8673

Jurnal Nasional Pendidikan Teknik Informatika (JANAPATI)

Volume 1, Nomor 1, Maret 2012

\subsection{Mikrokontroller ATmega 8535}

Mikrokontroler merupakan keseluruhan sistem komputer yang dikemas menjadi sebuah chip di mana di dalamnya sudah terdapat Mikroprosesor, I/O, Memori bahkan ADC, berbeda dengan Mikroprosesor yang berfungsi sebagai pemroses data (Heryanto, dkk, 2008:1).

Mikrokontroller AVR (Alf and Vegard's Risc processor) memiliki arsitektur 8 bit, dimana semua instruksi dikemas dalam kode 16-bit dan sebagian besar instruksi dieksekusi dalam 1 siklus clock atau dikenal dengan teknologi RISC (Reduced Instruction Set Computing). Secara umum, AVR dapat dikelompokan ke dalam 4 kelas, yaitu keluarga AT90Sxx, keluarga ATMega dan AT86RFxx. Pada dasarnya yang membedakan masing-masing adalah kapasitas memori, peripheral dan fungsinya

\section{Rancang Bangun}

\subsection{Diagram Blok Rangkaian}

Berikut skema rangkaian pendeteksi kebakaran dengan menggunakan mikrokontroller ATmega 8535 yang akan dibuat pada alat ini.

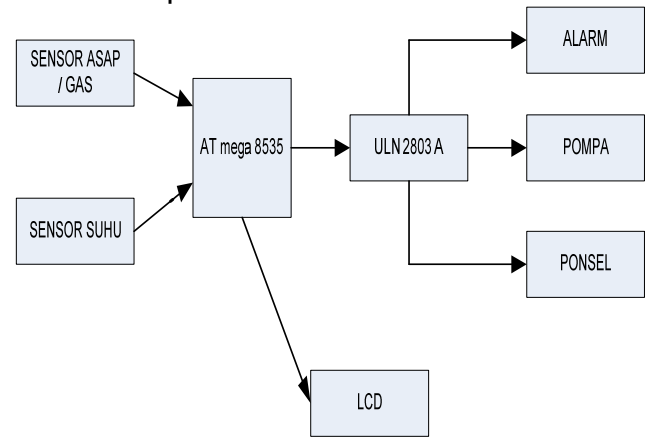

Gambar 3 Diagram rangkaian aplikasi teknologi GSM/GPRS pada sistem pendeteksi kebakaran dengan mikrokontroller ATmega 8535

\subsection{Perancangan Perangkat Lunak}

Dalam membuat perangkat lunak (software) yang pertama harus adalah menentukan alur programnya (flowchart). Dari flowchart dapat dibuat realisasi programnya. Di dalam program terdapat program utama ( main unit). Pada diagram flowchart terdiri dari 3 bagian, bagian yang pertama adalah flowchart keseluruhan dari alat pendeteksi kebakaran, bagian yang kedua merupakan flowchart dengan sensor suhu LM 35, dan yang terakhir flowchart dengan sensor gas TGS2610. 
ISSN 2089-8673

Jurnal Nasional Pendidikan Teknik Informatika (JANAPATI)

Volume 1, Nomor 1, Maret 2012

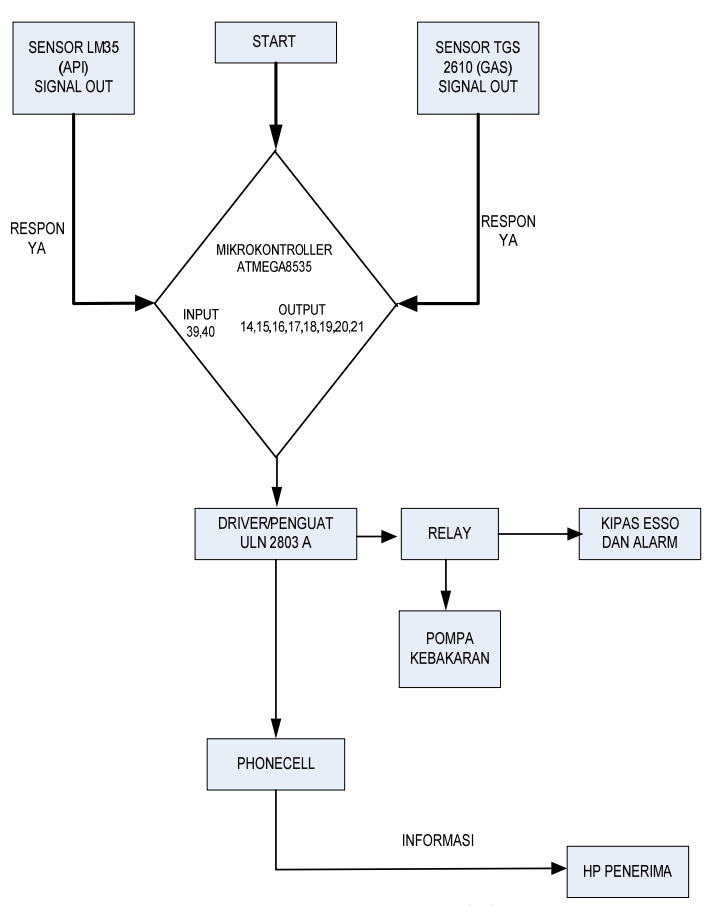

Gambar 4 Main unit flowchart aplikasi teknologi GSM pada sistem pendeteksi kebakaran berbasis mikrokontroller ATmega 8535

Gambar dibawah ini adalah flowchart dengan sensor suhu LM 35 aplikasi teknologi GSM pada sistem pendeteksi kebakaran berbasis mikrokontroller ATmega 8535.

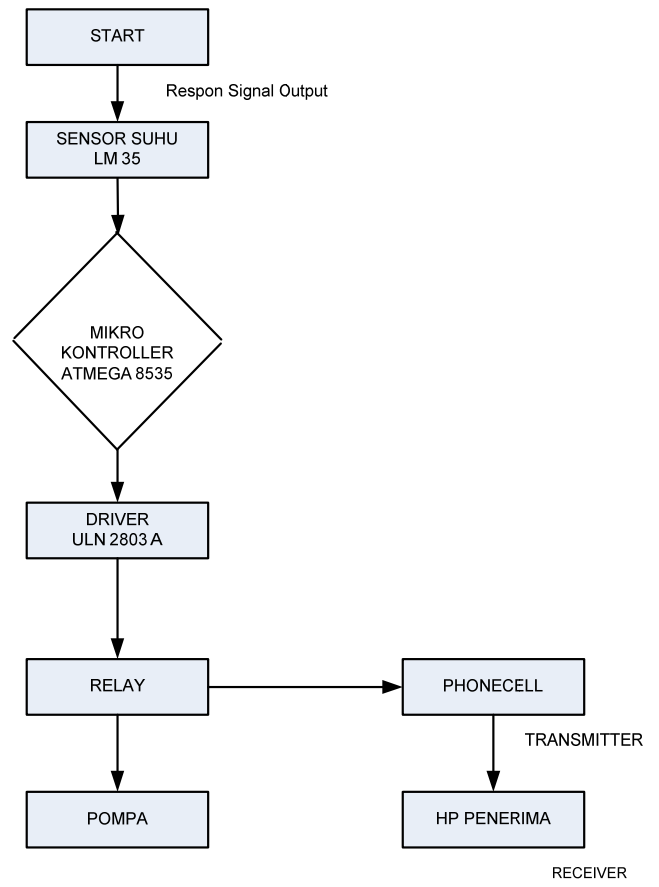

Gambar 5 Flowchart dengan sensor suhu LM 35 aplikasi teknologi GSM pada sistem pendeteksi kebakaran berbasis mikrokontroller ATmega 8535 
ISSN 2089-8673

Jurnal Nasional Pendidikan Teknik Informatika (JANAPATI)

Volume 1, Nomor 1, Maret 2012

Gambar 6 adalah flowchart dengan sensor gas TGS 2610 aplikasi teknologi GSM pada sistem pendeteksi kebakaran berbasis mikrokontroller ATmega 8535.

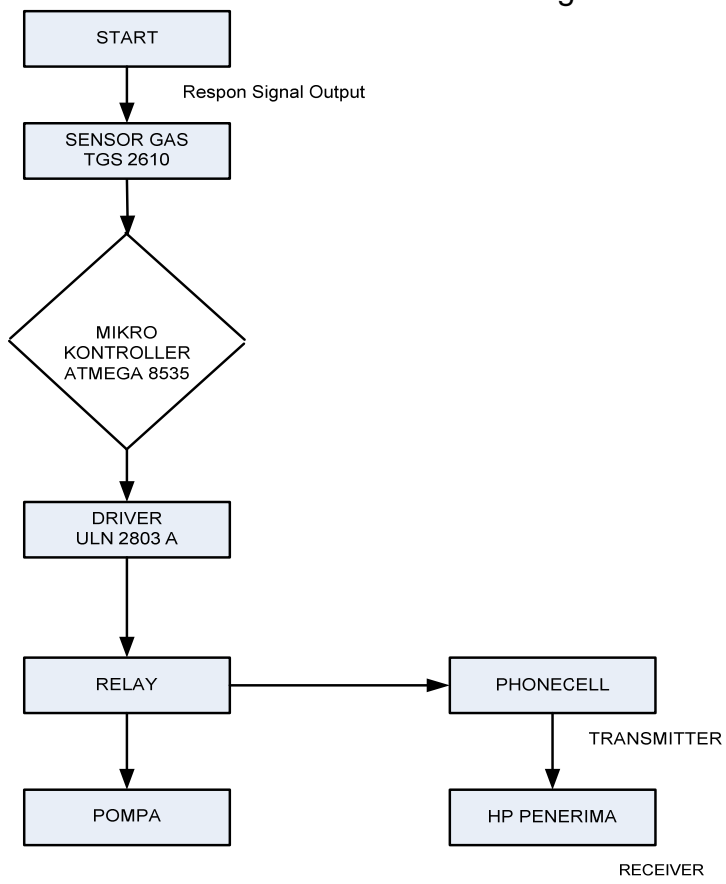

Gambar 6 Flowchart dengan sensor gas TGS 2610 aplikasi teknologi GSM pada sistem pendeteksi kebakaran berbasis mikrokontroller ATmega 8535

Pada rangkaian dibawah ini, dapat kita lihat bahwa sensor asap dan gas terhubung dengan mikrokontroller ATmega8535 yang dihubungkan dengan LCD. ATmega8535 terhubung dengan driver ULN2803A yang terhubung ke alarm, ponsel, dan pompa. Gambar dibawah ini menunjukkan rangkaian aplikasi teknologi GSM pada sistem pendeteksi kebakaran dengan mikrokontroller ATmega8535.

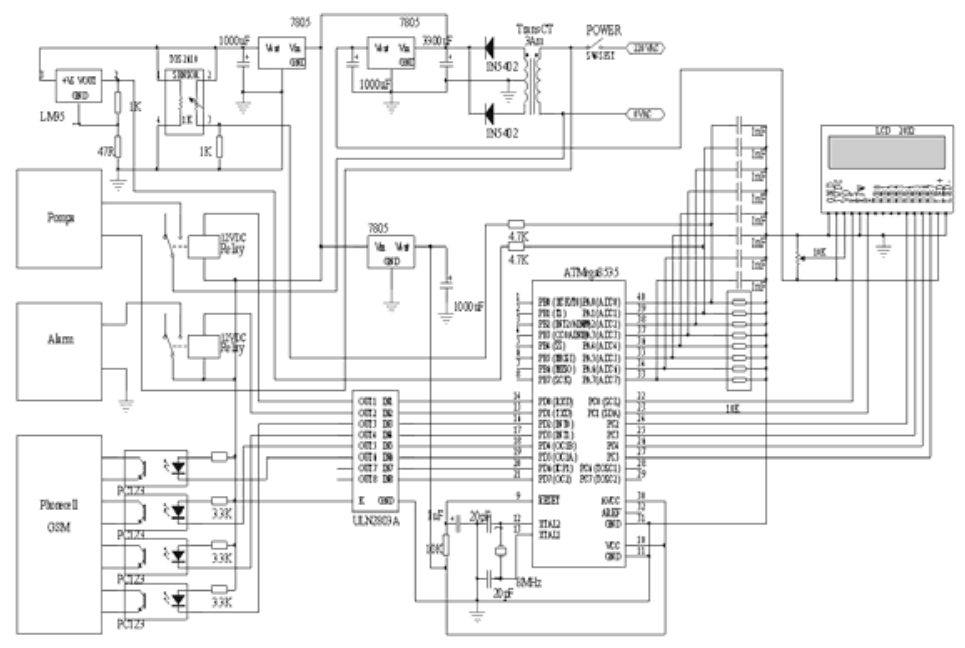

Gambar 7 Gambar rangkaian aplikasi teknologi GSM pada sistem pendeteksi kebakaran berbasis mikrokontroller ATmega 8535 
ISSN 2089-8673

Jurnal Nasional Pendidikan Teknik Informatika (JANAPATI)

Volume 1, Nomor 1, Maret 2012

\section{Pembahasan}

4.1 Hasil pengukuran pada saat sensor suhu dan gas aktif

Titik Uji di sensor TGS2610

Input $=$ TGS 2610

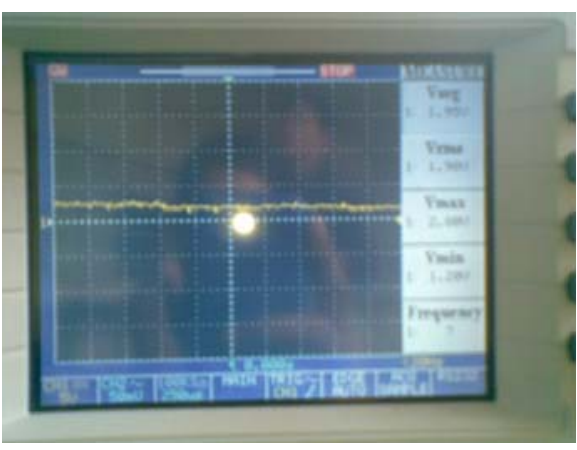

Gambar 8 Pengukuran Pada Sensor Suhu dan Gas

Keterangan:

$$
\begin{array}{ll}
\text { Volt/div } & =5 \mathrm{~V} / \mathrm{div} \\
\text { Time/div } & =250 \mathrm{~ms} \\
\text { Hasil : Vdc } & =0,3 \text { div } \times 5 \text { volt } \\
& =1,5 \text { volt }
\end{array}
$$

Pada titik pengukuran pada saat sensor suhu dan gas aktif maka tegangan yang dihasilkan mengalami penurunan sehingga tegangan yang didapatkan sebesar 1,5 volt. Hal ini terjadi karena masing-masing sensor bekerja pada resistansi yang berbeda sehingga mempengaruhi keluaran (output) tegangan yang dihasilkan.

4.2 Pengujian Alat Secara Keseluruhan Pengujian alat secara keseluruhan dilakukan dengan cara merangkai semuakomponen berdasarkan blok diagram yang telah dirancang dan memasukkan file hexademimal dari program yang telah dibuat berdasarkan data-data validasi daripengujian rangkaian sensor, mikrokontroller dan handphone.

Dari hasil pengujian yang dilakukan dimana pengiriman pesan dari ke nomor handphone tujuan telah berhasil terkirim. Pada pengujian ini waktu mengirim pesan dari handphone tujuan berdasarkan settingan program berbeda dengan waktu pada saat pengujian.

Tabel 1 Hasil Pengujian Pengiriman Pesan

\begin{tabular}{|l|c|l|c|c|}
\hline No & $\begin{array}{c}\text { Nomor } \\
\text { Handphone } \\
\text { Penerima }\end{array}$ & Hasil & $\begin{array}{c}\text { Hasil Pesan terkirim } \\
\text { berdasarkan settingan } \\
\text { program(detik) }\end{array}$ & $\begin{array}{c}\text { Pesan terkirim } \\
\text { berdasarkan pengujian } \\
\text { (detik) }\end{array}$ \\
\hline 1 & $0816328 x x x x$ & $\begin{array}{l}\text { Pesan } \\
\text { Terkirim }\end{array}$ & 3 & 8 \\
\hline 2 & $0813778 x x x x$ & $\begin{array}{l}\text { Pesan } \\
\text { Terkirim }\end{array}$ & 6 & 11 \\
\hline 3 & $0856692 x x x x$ & $\begin{array}{l}\text { Pesan } \\
\text { Terkirim }\end{array}$ & 9 & 23 \\
\hline 4 & $0812781 \times x x x$ & $\begin{array}{l}\text { Pesan } \\
\text { Terkirim }\end{array}$ & 12 & 26 \\
\hline 5 & $0877948 x x x x$ & $\begin{array}{l}\text { Pesan } \\
\text { Terkirim }\end{array}$ & 14 & \\
\hline
\end{tabular}


Dari tabel diatas dimana waktu untuk mengirim pesan dari ke handphone berdasarkan pengujian mempunyai tota Iwaktu selama 26 detik, sedangkan dari settingan program membutuhkan waktu selama 14 detik. Perbedaan waktu ini disebabkan karena adanya kepadatan jaringan padaoperator SMSC (Short Message Senvice Center) sehingga pesan yang dikirim ke masing - masing nomor tidak sesuai dengan waktu yang diatur dalam program. Akan tetapi meskipun terjadi perbedaan waktu pada pengujian diatas telah berhasil dilakukan.

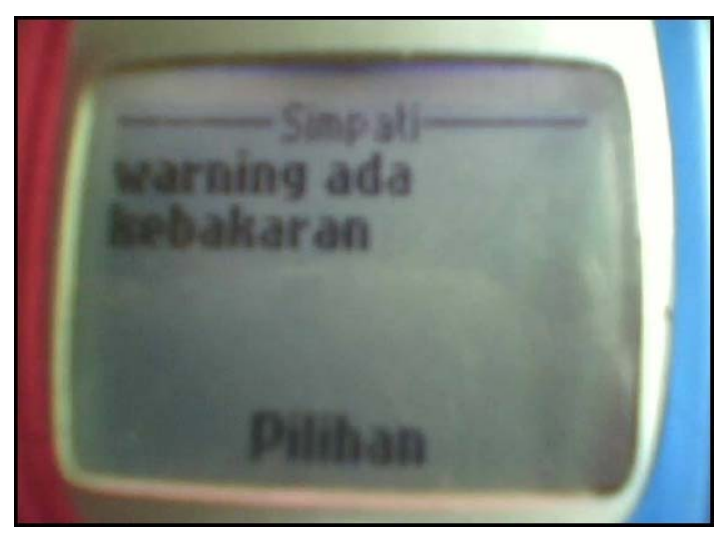

Gambar 9 Tampilan Isi SMS

Adapun gambaran miniatur system pendeksi kebakaran secara keseluruhan dapat dilihat pada gamabr 10 dibawah ini.
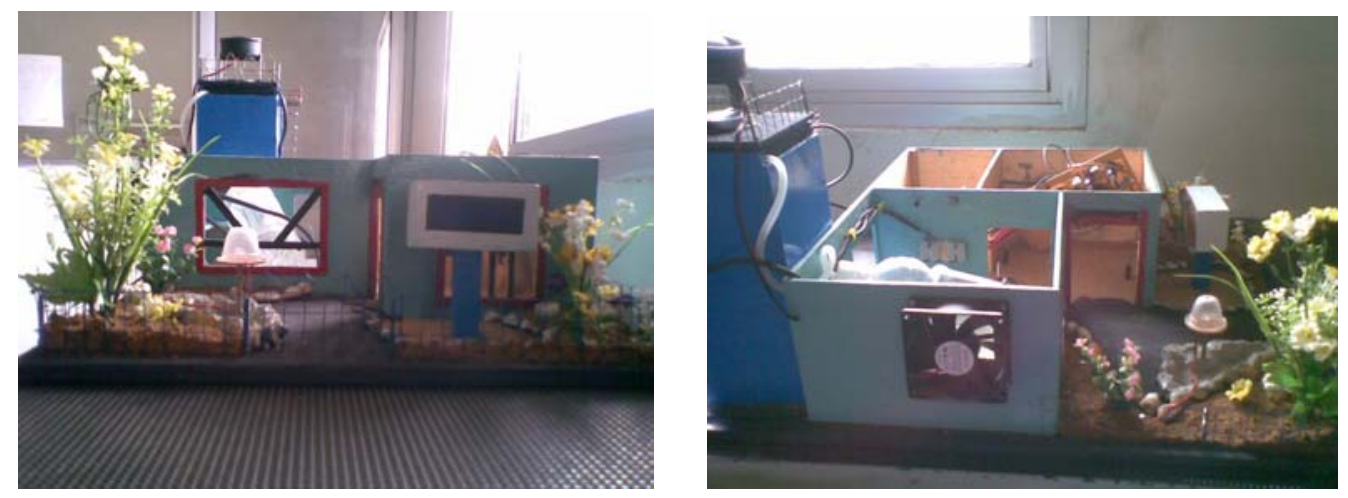

Gambar 10 Gambar miniatur alat pendeteksi kebakaran

\section{Kesimpulan Dan Saran}

\subsection{Kesimpulan}

1. Ketika salah satu atau kedua sensor aktif / mendeteksi adanya kebakaran informasi akan dikirimkan mikrokontroller ATmega85 dan dibawa ke penguat/ driver ULN 2803A dan alarm akan menyala. Sensor akan mendeteksi adanya perubahan suhu dan juga tekanan gas mulai dari 500 ppm - 10.000 ppm.

2. Hasil deteksi dari sensor gas TGS 2610 dan sensor api atau suhu LM 35 akan diproses di dalam mikrokontroller ATMEGA 8535 dengan input masing-masing dikaki 39 dan kaki 40 dengan output dikaki 14 dan 15 menuju rangkaian driver/penguat ULN2803A dan diteruskan ke relay yang akan mengaktifkan sistem untuk menyalakan alarm, ponsel, dan pompa air mini yang telah terkoneksi satu sama lain. 
ISSN 2089-8673

Jurnal Nasional Pendidikan Teknik Informatika (JANAPATI)

Volume 1, Nomor 1, Maret 2012

3. Ketika sensor mendeteksi adanya kebakaran, handphone base akan mengirimkan pemberitahuan kepada handphone personal bahwa telah terjadi kebakaran dengan media SMS (Short Message Service).

4. Telepon selular yang berfungsi sebagai pengirim alamat rumah telah berhasil mengirimkan pesan ke handphone penerima.

\subsection{Saran}

1. Lakukan pengecekan secara teratur untuk ketersediaan catu daya pada ponsel, sensor gas dan sensor suhu.

2. Untuk pengembangan alat ini dapat menggunakan sensor suhu lebih dari satusehingga dapat ditempatkan ke segala sisi pada suatu bangunan rumah.

\section{DAFTAR PUSTAKA}

Andrianto, Heri. 2008. Pemrograman Mikrokontroller AVR ATMEGA16 Menggunakan Bahasa C(Code Vision AVR). Bandung: Informatika.

Ariel Palazzesi, 2010, Familia, http://www.ucontrol.com.ar/wiki/index.php?title=LM78xx,

Budiharto, Widodo. 2007. Belajar sendiri 12 proyek mikrokontroller untuk pemula. Andi.Offset:Yogyakarta

Handoko, Djati,OTOMATISASI SISTEM PENANGANAN KEBAKARANBERBASIS MIKROKONTROLER IC AT MEGA 8535, Seminar Nasional Sains danTeknologi-II 2008 Universitas Lampung, 17-18 November 2008 